\title{
CULTIVO DA MAMONEIRA INFLUENCIADA POR DIFERENTES POPULAÇÕES DE PLANTAS $\left({ }^{1}\right)$
}

\author{
TÂNIA KRISTINA MACHADO COSTA BIZINOTO $\left({ }^{2}\right)$; ELISA GUIMARÃES DE OLIVEIRA $\left({ }^{2}\right)$; \\ SABRINA BRITO MARTINS $\left({ }^{2}\right)$; SANDRO ÂNGELO DE SOUZA $\left({ }^{3}\right)$ MIRIAN GOTARDO $\left({ }^{3}\right)$
}

\begin{abstract}
RESUMO
O estudo teve por objetivo avaliar o desenvolvimento e a produtividade da cultura da mamoneira cultivar Guarani, influenciada por diferentes populações de plantas, em sequeiro. O experimento foi realizado em Bom Jesus (GO). Utilizou-se o delineamento de blocos ao acaso com quatro repetições. Foram realizados cinco tratamentos: Tratamento $\mathrm{n}^{\mathrm{o}} 1-1 \times 1 \mathrm{~m}$ com 10.000 plantas ha ${ }^{-1}$; Tratamento $\mathrm{n}^{\circ}{ }^{\circ} 2-$ $0,90 \times 0,70 \mathrm{~m}^{\text {com }} 15.873$ plantas ha $^{-1}$; Tratamento $\mathrm{n}^{\mathrm{o}} 3-1 \times 0,50 \mathrm{~m}$ com 20.000 plantas ha ${ }^{-1}$; Tratamento $\mathrm{n}^{\circ}$ 4- 0,90 × 0,50 m com 22.222 plantas ha-1; Tratamento $\mathrm{n}^{\circ}$ 5- 1,50 × 0,50 m com 13.333 plantas ha $^{-1}$. Foram colhidos dados de altura de plantas, altura de inserção do $1^{\circ}$ racemo, número de racemos por planta, comprimento de racemos, diâmetro caulinar e produtividade. A altura do primeiro racemo, o número de racemos por planta e o diâmetro do caule foram influenciados pelas diferentes populações de plantas; para altura de planta, comprimento de racemos e produtividade, não houve qualquer efeito significativo entre os tratamentos.
\end{abstract}

Palavras-chave: Ricinus communis, oleaginosa, diâmetro caulinar.

\section{ABSTRACT \\ CASTOR BEAN CROP INFLUENCED BY DIFFERENT POPULATION OF PLANTS}

The experiment was carried out in Bom Jesus, Goiás State, Brazil, with the objective to evaluate the growth and yield of the castor crop bean, cultivar Guarani, influenced by different population, of plants under rainfed condition. A randomized block design was used. Five treatments had been carried through: Treatment $\mathrm{n}^{\mathrm{o}} 1-1 \times 1 \mathrm{~m}$ with 10,000 plants ha ${ }^{-1}$; Treatment $\mathrm{n}^{\mathrm{o}} 2-0.90 \times 0.70 \mathrm{~m}$ with 15,873 plants ha ${ }^{-1}$; Treatment $\mathrm{n}^{\mathrm{o}} 3-1 \times 0.50 \mathrm{~m}$ with 20,000 plants ha ${ }^{-1}$; Treatment $\mathrm{n}^{\circ} 4-0.90 \times 0.50 \mathrm{~m}$ with 22,222 plants ha-1; Treatment $\mathrm{n}^{0} 5-1,50 \times 0,50 \mathrm{~m}$ with 13,333 plants ha ${ }^{-1}$. Data of height of plants, first raceme height, number of raceme per plant, length of raceme, stem diameter, and yield were collected. The first raceme height, the number of raceme per plant and the stem diameter were influenced by different population of plants. However for the height of plant, length of raceme and yield, there was no significant effect among the treatments.

Key words: Ricinus communis, oilseed, stem diameter.

$\left.{ }^{1}\right)$ Recebido para publicação em 03 de junho de 2008 e aceito em 22 de outubro de 2008.

$\left({ }^{2}\right)$ Graduados pelo Instituto Luterano de Ensino Superior de Itumbiara - ILES/ULBRA, Av. Beira Rio, n. ${ }^{\circ} 1001$ 75523-200 Itumbiara (GO). E-mail:taniabizinoto@yahoo.com.br; elisaitb@yahoo.com.br; sabrina.brito@yahoo.com.br

$\left({ }^{3}\right)$ Curso de Agronomia do Instituto Luterano de Ensino Superior de Itumbiara - ILES/ULBRA, Av. Beira Rio, n. ${ }^{\circ}$ 1001, 75523-200 Itumbiara (GO). E-mail: mgotardo@netsite.com.br, sandroasouza@yahoo.com.br. 
A mamoneira (Ricinus communis L) é uma planta de origem tropical, resistente à seca e exigente em calor $\left(20\right.$ a $\left.30{ }^{\circ} \mathrm{C}\right)$ e luminosidade. Para o seu crescimento e desenvolvimento são necessários pelo menos $500 \mathrm{~mm}$ de precipitação pluvial. Pode ser produzida em altitudes variáveis de 300 a 1.500 metros e semeada em vários tipos de solo, exceto nos muito argilosos, sujeitos a encharcamento, salinos e ou sódicos, com elevado teor de sódio trocável (AMARAL, 2002).

Segundo Santos et al. (2001), da industrialização da mamona obtém-se, como produto principal, o óleo e, como subproduto, a torta, utilizada na restauração de terras esgotadas, com destaque na lavoura fumageira na Bahia.

A mamona é uma das fontes de matéria-prima para produção de energia renovável que poderia ser o suporte de projetos de Mecanismos de Desenvolvimento Limpo, destinados à fixação do carbono ou à redução da sua emissão e para retirada dos gases poluentes (SAVY FILHO, 2005).

Segundo a Conab (2008), na safra 2007/2008 a área plantada no Brasil foi de 163,8 mil hectares, com produtividade de 804 quilos por hectare e produção de 131,8 mil toneladas. A estimativa de área plantada para a safra 2008/2009 é de $164,5 \mathrm{mil}$ hectares, com produtividade de 789 quilos por hectare e produção de 130 mil toneladas. A mamona é aproveitada em mais de 500 itens pela indústria química. Cerca de $93 \%$ da produção do país estão no Nordeste. O aumento na safra atual é resultado de um crescimento de área de $7,3 \%$ e de melhoria na produtividade, que teve um incremento de $45,3 \%$, quando comparada a períodos anteriores. Os agricultores estão colhendo, em média, 875 quilos por hectare. Durante a safra 1997/1998, por exemplo, a colheita era de apenas 142 quilos por hectare. Nos primeiros seis meses de 2008, foram arrecadados US\$ 6,18 milhões com as exportações de óleos derivados da mamona no Brasil e embarcadas 3.416 toneladas para fora do país. O produtor recebe, em média, $\mathrm{R} \$ 74$ pela saca de 60 quilos.

Para que se possa aperfeiçoar o sistema de produção dessa cultura, é preciso determinar o espaçamento entre linhas e a distância entre plantas mais adequados para diferentes situações, considerando-se características do clima e solo da região de cultivo e as características da cultivar a ser adotada. A escolha da população adequada de plantas é uma prática cultural extremamente simples, porém de grande impacto na produtividade e em diversos aspectos da lavoura, como controle de plantas daninhas, colheita e uso de implementos agrícolas (SEVERINo et al., 2006).
O objetivo deste experimento foi determinar populações de plantas mais favoráveis ao desenvolvimento e à produtividade da cultura da mamoneira cultivar Guarani, em regime de sequeiro, em Bom Jesus (GO).

O experimento foi implantado no ano agrícola 2006/2007 na Fazenda Galvão, localizada no município de Bom Jesus (GO), com $480 \mathrm{~m}$ de altitude, $18^{\circ} 08^{\prime} 16^{\prime \prime}$ latitude Sul e $50^{\circ} 04^{\prime} 31^{\prime \prime}$ longitude Oeste e clima quente e úmido. A precipitação pluvial é variável entre $1600 \mathrm{~mm}$ e $1800 \mathrm{~mm}$, com chuvas regulares nos meses de outubro a abril e período seco entre maio e setembro. A área destinada à implantação do experimento foi cultivada anteriormente com soja, colhida em abril de 2006, ficando o solo em pousio até a época do preparo para o cultivo da mamona. O solo foi preparado com subsolador e grade intermediária, semeando-se a cultivar Guarani.

Adotou-se o delineamento experimental de blocos ao acaso com cinco tratamentos e quatro repetições. O tamanho das parcelas foi de $22 \times 18 \mathrm{~m}$ $\left(396 \mathrm{~m}^{2}\right)$, perfazendo uma área total de $10.000 \mathrm{~m}^{2}$.

Foram testados cinco tratamentos com diferentes arranjos populacionais: $1 \times 1 \mathrm{~m}$ com 10.000 plantas, ha-1; $0,90 \times 0,70 \mathrm{~m}$ com 15.873 plantas ha-1; $^{-1}$; $1 \times 0,50 \mathrm{~m}$ com 20.000 plantas ha ${ }^{-1} ; 0,90 \times 0,50 \mathrm{~m}$ com 22.222 plantas ha ${ }^{-1}$ e $1,50 \times 0,50 \mathrm{~m}$ com 13.333 plantas ha ${ }^{-1}$. A área foi adubada conforme recomendação agronômica, após realização de análise de solo, com $250 \mathrm{~kg} \mathrm{ha}^{-1}$ do formulado 4-20-20, aplicados por cova, na semeadura, e $40 \mathrm{~kg} \mathrm{ha}^{-1}$ de nitrogênio aos 42 dias após a emergência.

A semeadura da mamona foi manual, realizada em dezembro de 2006, em covas com profundidade de $8 \mathrm{~cm}$ e dispostas duas sementes por cova, com posterior desbaste. A adubação com fertilizantes químicos foi feita na mesma cova.

O controle de plantas daninhas e demais tratos culturais foram realizados conforme o desenvolvimento e a necessidade da cultura.

A fim de se verificar o efeito dos espaçamentos nos caracteres agronômicos, foram avaliadas 15 plantas por parcela, escolhidas ao acaso. Foram medidas a altura das plantas; altura de inserção do primeiro racemo e comprimento dos racemos com uma trena; contagem do número de racemos por planta e medição do diâmetro de caules com paquímetro.

Em junho, foi realizada a colheita manual da mamona, em quatro linhas centrais, desprezando-se as bordaduras. Posteriormente, os racemos colhidos foram debulhados e distribuídos em terreiro para a uniformidade da umidade, sendo então descascados 
em máquina de beneficiamento de mamona, Mamoneira NUX, BMW 30; as sementes foram ensacadas e pesadas.

Os dados obtidos foram submetidos à análise de variância e as médias comparadas pelo teste de Duncan ao nível de 5\%. O efeito da população de plantas nas características avaliadas foi analisado por regressão linear.

O resumo da análise de variância das características avaliadas está apresentado na tabela 1. Algumas características, como: altura do primeiro racemo, número de racemos por planta, diâmetro do caule, relacionadas ao desenvolvimento da planta, foram influenciadas pelas diferentes populações de plantas. Os quadrados médios obtidos nas análises de variância (Tabela 1) não foram significativos para as características altura de plantas, comprimento de racemos e produtividade. Quanto aos coeficientes de variação experimentais verificou-se amplitude de variação de $7,3 \%$ para altura do primeiro racemo a $26,9 \%$ para o número de racemos por planta, sendo considerados normais para características quantitativas.

A altura de inserção do primeiro racemo, o número de racemos e o diâmetro caulinar foram influenciados nas diversas populações de plantas (Figuras 1, 2 e 3).

Tabela 1. Resumo da análise de variância para os caracteres altura de planta, altura do primeiro racemo, número de racemos por planta, diâmetro do caule e produtividade. Fazenda Galvão, Bom Jesus de Goiás (GO), 2006/2007

\begin{tabular}{|c|c|c|c|c|c|c|c|}
\hline \multirow[b]{2}{*}{ FV } & \multirow[b]{2}{*}{ GL } & \multicolumn{6}{|c|}{ Quadrado Médio } \\
\hline & & $\begin{array}{c}\text { Altura da } \\
\text { planta }\end{array}$ & $\begin{array}{l}\text { Altura do } 1 .^{\circ} \\
\text { racemo }\end{array}$ & Racemos/planta & $\begin{array}{c}\text { Comprimento } \\
\text { de racemos }\end{array}$ & $\begin{array}{c}\text { Diâmetro do } \\
\text { caule }\end{array}$ & Produtividade \\
\hline & & \multicolumn{2}{|c|}{$\mathrm{m}$} & n. ${ }^{\mathrm{o}}$ & \multirow{2}{*}{$\begin{array}{c}\mathrm{m} \\
0,0036^{\mathrm{ns}}\end{array}$} & \multirow{2}{*}{$\begin{array}{c}\mathrm{mm} \\
32,8025^{* *}\end{array}$} & \multirow{2}{*}{$\begin{array}{c}\mathrm{kg} \mathrm{ha}^{-1} \\
66191,1467^{\mathrm{ns}}\end{array}$} \\
\hline Tratamentos & 4 & $0,0658^{\mathrm{ns}}$ & $0,1165^{* *}$ & $1,605^{*}$ & & & \\
\hline Bloco & 3 & 0,0016 & 0,0171 & 0,2766 & 0,0047 & 9,7874 & 48451,2354 \\
\hline Resíduos & 12 & 0,0467 & 0,0077 & 0,331 & 0,0033 & 5,3699 & 142338,3154 \\
\hline $\mathrm{CV}(\%)$ & & & & 26,9 & 10,5 & 7,7 & 24,5 \\
\hline
\end{tabular}

***,* e ns: correspondem respectivamente a significativo a $1 \%$, a $5 \%$ e não-significativo a $5 \%$ pelo Teste $\mathrm{F}$

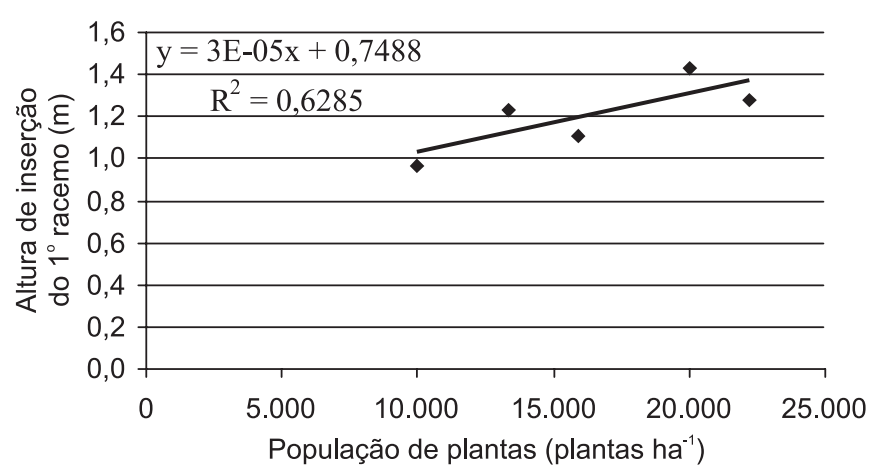

Figura 1. Relação entre população de plantas e altura média de inserção do $1 .^{\circ}$ racemo.

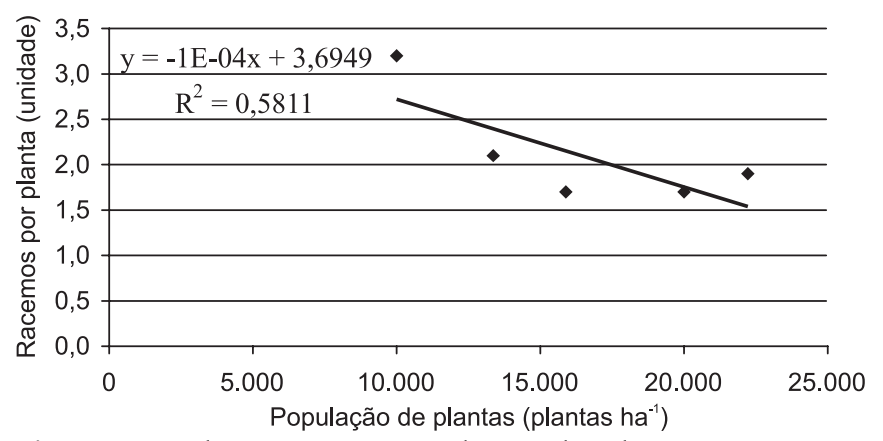

Figura 2. Relação entre população de plantas e número médio de racemos por planta.

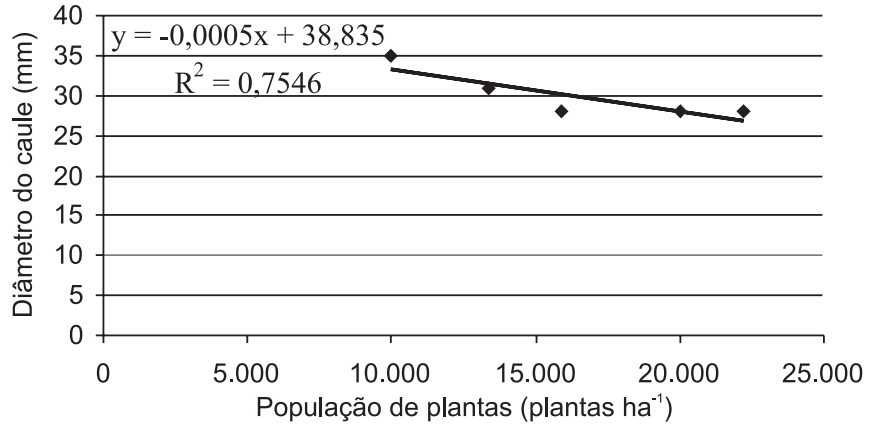

Figura 3. Relação entre população de plantas e diâmetro médio do caule.

No maior espaçamento, o espaço para o crescimento vegetativo da cultura foi maior, sendo determinados menor altura de inserção do primeiro racemo, maior número de racemos e maior diâmetro caulinar. Nos menores espaçamentos, houve diminuição no número de racemos, porém essa diminuição foi compensada pelo maior número de plantas em uma mesma área. Nos menores espaçamentos ocorreu também maior altura de inserção do primeiro racemo e menor diâmetro caulinar, possivelmente devido ao estiolamento provocado pela competição por luz. 
Resultados semelhantes foram determinados por SEverino et al. (2006), os quais não verificaram influência na altura das plantas pela alteração do espaçamento entre linhas, mas apenas na altura de inserção do primeiro racemo e no diâmetro do caule. Gondim et al. (2004) não constataram influência significativa do adensamento em quaisquer das características avaliadas, tais como, altura do primeiro racemo, altura da planta, diâmetro do caule, número de racemos, comprimento de racemos e produtividade; no entanto, a produtividade foi aumentada em $78 \%$ no genótipo de porte médio e em $104 \%$ no genótipo de porte anão (Tabela 2). Houve alguma tendência de aumento da altura e diminuição do número de racemos por planta com o aumento da população. Os autores verificaram ainda, que, para o genótipo CSRN142 , com o adensamento de semeadura houve contribuição para aumento de produtividade de sementes em mais de $60 \%$, mas não interferência na altura das plantas.

Tabela 2. Médias de altura de planta e do primeiro racemo, número de racemos por planta, diâmetro do caule e produtividade. Fazenda Galvão, Bom Jesus de Goiás, (GO), 2006/2007

\begin{tabular}{|c|c|c|c|c|c|c|}
\hline $\begin{array}{l}\text { População } \\
\text { plantas.ha }^{-1}\end{array}$ & $\begin{array}{c}\text { Altura } \\
\text { da planta }\end{array}$ & $\begin{array}{c}\text { Altura de inserção } \\
\text { do } 1^{\circ} \text { racemo }\end{array}$ & $\begin{array}{l}\text { Racemos por } \\
\text { planta }\end{array}$ & $\begin{array}{c}\text { Comprimento } \\
\text { de racemos }\end{array}$ & $\begin{array}{l}\text { Diâmêtro } \\
\text { do caule }\end{array}$ & Produtividade \\
\hline & \multicolumn{2}{|c|}{$\mathrm{m}$} & $\mathrm{n}^{\mathrm{o}}$ & $\mathrm{m}$ & $\mathrm{mm}$ & $\mathrm{kg} \mathrm{ha}^{-1}$ \\
\hline 10.000 & $2,38 \mathrm{a}$ & $0,97 c$ & $3,2 a$ & $0,54 a$ & $35 a$ & $1.721 \mathrm{a}$ \\
\hline 15.873 & $2,07 a$ & $1,11 b c$ & $1,7 b$ & $0,50 \mathrm{a}$ & $28 b$ & $1.397 \mathrm{a}$ \\
\hline 20.000 & $2,34 \mathrm{a}$ & $1,43 a$ & $1,7 \mathrm{~b}$ & $0,56 a$ & $28 b$ & $1.611 \mathrm{a}$ \\
\hline 22.222 & $2,36 a$ & $1,28 \mathrm{ab}$ & $1,9 b$ & $0,58 \mathrm{a}$ & $28 b$ & $1.536 \mathrm{a}$ \\
\hline 13.333 & $2,32 \mathrm{a}$ & $1,23 \mathrm{ab}$ & $2,1 \mathrm{ab}$ & $0,54 a$ & $31 \mathrm{ab}$ & $1.450 \mathrm{a}$ \\
\hline
\end{tabular}

Médias nas colunas, seguidas pelas mesmas letras, não são diferentes entre si, pelo teste de Duncan, a 5\% significância

Novas pesquisas deverão ser direcionadas ao desenvolvimento de cultivares adaptadas aos menores espaçamentos, visando às plantas com características favoráveis ao desenvolvimento da lavoura. Plantas de menor porte são vantajosas ao controle de plantas daninhas, no estádio da colheita mecanizada, à utilização de implementos agrícolas, à incorporação dos restos culturais e, com isso, pode-se ter redução do custo de produção e aumento das áreas de cultivo dessa cultura, limitado pelo elevado custo de mão-de-obra.

Em condições de sequeiro, para a cultura da mamona cultivar Guarani, a altura do $1 .^{\circ}$ racemo é positiva e diretamente relacionada à população de plantas. O número de racemos por planta e o diâmetro do caule são positiva e inversamente relacionados à população de plantas. Todavia, a produtividade da cultura não foi influenciada pelo número de plantas por hectare.

\section{AGRADECIMENTOS}

À empresa Caramuru Alimentos S/A pelo apoio técnico e logístico para a execução deste estudo.

\section{REFERÊNCIAS}

AMARAL, J. G. C. do. Mamona al Guarany. Campinas: Coordenadoria de Assistência Técnica Integral (CATI). 2002 Disponivel em:http:// www.cati.sp.gov.br. Acesso em 18 dez. 2006.

CONAB. Companhia Nacional de Abastecimento. Brasília. out. 2008. Disponível em : http://www.conab.gov.br Acesso. em 05 dez. 2008.

GONDIM, T. M. de S. et al. Adensamento de mamoneira sob irrigação em Barbalha, CE. In: CONGRESSO BRASILEIRO DE MAMONA, 1., 2004, Campina Grande, PB. Resumos.... Campina Grande, PB: Embrapa Algodão, 2004 v.1. p.17.

SANTOS, R.F.; BARROS, A.L.; MARQUES, F.M.; FIRMINO, P.T.; REQUIÃO, L.E.G. Análise econômica. In: AZEVEDO, D.M.P.; LIMA, E.F. (Eds.). O agronegócio da mamona no Brasil. EMBRAPA-SPI, 2001. p.17-35.

SAVY FILHO, A. Mamona: tecnologia agrícola. Campinas: EMOPI, 2005.105p.

SEVERINO L.S. et al. Crescimento e produtividade da mamoneira influenciada por plantio em diferentes espaçamentos entre linhas. Revista Ciência Agronômica, v.37, p.50-54, 2006. 